\title{
An Experimental and Algorithm Research on the Influence of OTO Teaching Mode on College Students' PE Learning Interest Based on Cloud Computing
}

\author{
Shijun $W u\left(\mathbb{D},{ }^{1,2,3}\right.$ Jianghong Dai $\mathbb{D}^{3}$ and Jiujiu Yang $\mathbb{C}^{3}$ \\ ${ }^{1}$ School of Physical Education and Health, East China Normal University, Shanghai 200241, China \\ ${ }^{2}$ Key Laboratory of Adolescent Health Assessment and Exercise Intervention of Ministry of Education, Shanghai 200241, China \\ ${ }^{3}$ School of Physical Education, Hunan University of Humanities, Science and Technology, Loudi, Hunan 417000, China
}

Correspondence should be addressed to Shijun Wu; wsj151978498@163.com

Received 26 August 2021; Accepted 6 October 2021; Published 9 November 2021

Academic Editor: Punit Gupta

Copyright (c) 2021 Shijun Wu et al. This is an open access article distributed under the Creative Commons Attribution License, which permits unrestricted use, distribution, and reproduction in any medium, provided the original work is properly cited.

Algorithm is a step of problem-solving, and algorithm can be defined as any special method for solving a certain type of problem. In computer science, algorithms are described in computer algorithm language and represent accurate and effective methods for solving a class of problems with computers. In order to verify the role of the OTO teaching mode from the perspective of cultivating learning interest and to provide a practical basis for the reform of physical education in colleges and universities, 107 second-year physical education majors in a common university were selected as experimental subjects and divided into an experimental group and a control group, and the two groups were intervened through a 16-week experiment. Multivariate covariance was used to analyze the influence of two teaching modes on college students' interest in sports learning. After excluding factors such as student gender, physical exercise behavior stage, football learning experience, and physical health, the groups have statistical significance in the four dimensions of positivity, skill learning, extracurricular activities, and negativity in sports learning interest. However, there is no significant difference in the influence of sports attention on sports learning interest. The research proves that the application of OTO teaching mode is conducive to promoting students' learning positivity, technical learning, and extracurricular activities and alleviating students' negative learning emotions. The degree of attention to sports in the interest of sports learning is not very significant. It is suggested that colleges and universities adopt the OTO teaching mode in the teaching of general football courses.

\section{Introduction}

Being interested in a certain sport activity can encourage people to devote more time and energy to it, generate lasting attention, and maintain a clear perception. Interest is caused by the needs of the individual, and a tendency to engage in a certain activity is produced under the interaction of the individual's subjective state and environmental characteristics. It is a guarantee of motivation to promote and maintain the individual to continue to engage in a certain activity [1]. PE learning interest is the psychological state generated by the interaction between the individual's subjective state and the physical learning environment [2], and it is an important driving force for acquiring sports and health knowledge and skills and promoting the physical and mental health of students. It affects the direction and intensity of specific activities of people participating in sports. For example, the Opinions on Strengthening School Sports to Promote the Comprehensive Development of Students' Physical and Mental Health promulgated by the General Office of the State Council in 2016 pointed out that students should cultivate interest, develop exercise habits, and master sports skills [3].

As the work of campus football enters the 2.0 era, China attaches significant importance to the development of campus football and has introduced a lot of policies. Football has also made considerable progress among young people. However, some problems have also appeared in the teaching 
of football courses in colleges and universities, such as backward sports concepts, traditional teaching methods, single teaching methods in football courses $[4,5]$, and lack of attention to physical education. These greatly reduce the students' positivity for participating in football and their interest and positivity for football. The study found that with the continuous deepening of the new curriculum reform, higher physical education is also facing higher and newer requirements. The traditional teaching model is more and more difficult to adapt to the requirements of higher education, and not only it is not obvious enough to improve the physical quality of students but also it is not conducive to cultivating students' interest in learning [6].

The OTO teaching mode was first proposed by Alex Rampell in the United States. "OTO" means "online and offline" in Chinese. Scholars believe that the OTO teaching mode is a hybrid teaching that combines traditional classroom teaching and modern online education in the mobile Internet, big data, and cloud computing environment and effectively combines online learning resources and online learning tools with student learning and teacher teaching [7-9].

Therefore, the OTO teaching mode is not just a type of teaching form, but a new teaching method that uses all the information and tools on the mobile Internet and the intelligent application of mobile terminals to conduct interactive teaching through the network. In the case of the huge impact of the COVID-19 pandemic on education and teaching, the Ministry of Education requires the online course platform to follow "suspension of classes without cessation of learning, suspension of classes without cessation of teaching" which means that no matter when the school resumes classes, we must first keep the children in a state of learning during the epidemic. Based on this, this study adopts the online and offline hybrid teaching mode combining Chaoxing Learning Platform+Tencent WeChat Group in the teaching of football general courses, mainly using the Chaoxing Learning Platform as a platform to integrate the syllabus, teaching plan, PPT courseware, and teaching content. The teaching videos, animations, and other related materials are uploaded to the Chaoxing Learning Platform, and a teaching model of "online teaching, offline training" is formed [10]. At the same time, the provincial high-quality football online courses that come with the platform provide excellent teaching resources for students to study on their own [11]. On this basis, exploring the impact of OTO teaching mode on college students' interest in sports learning has important practical significance to the reform of college physical education and teaching.

\section{Research Objects and Methods}

2.1. Research Objects. Students in the second year in four football classes of a university's physical education major were selected as experimental subjects, including 51 in the experimental group and 56 in the control group (Table 1). Among them, the experimental class adopts the OTO teaching mode for teaching and the control class adopts the traditional teaching mode for teaching. Before and after the experiment, focus on students' PE learning interests (including positivity, negativity, skill learning, extracurricular activities, and sports attention) and football skills (including bumping the ball, passing on the inside of the foot, shooting around the club, and kicking far) were analyzed.

2.2. Teacher Settings. The Jianghong Dai is a teacher in the experimental group, specializing in football, has ten years of college football teaching experience, and has implemented certain research on online and offline teaching modes. The teacher in the control group is an old teacher of college football special teaching with 20 years of teaching experience. The teaching method is relatively traditional. He has participated in the compilation of traditional teaching plans and is familiar with the teaching content and process. Both groups of teachers are specialized in football, with rich teaching experience, serious teaching attitude, and good teaching effect.

2.3. Intervention Programme. The teaching plan of the experimental group was compiled by the author according to the structure and characteristics of the OTO course teaching mode. The teaching plan of the control group was prepared by the teachers of the general football course based on the syllabus of the teaching syllabus. It has gone through four years of teaching practice.

\subsubsection{Teaching Content Settings}

(1) Teaching content of each semester: the overall teaching content of the experimental group and the control group is the same, including basic theories, basic techniques (inner foot pass, bump, 20M round shot, long kick), basic tactics (two-over-one cooperation, defensive counterattack), physical fitness (speed, strength, flexibility, bounce, agility), and examination (technical, quality examination). However, the design concept of the teaching schedule is not the same. The experimental group is based on the OTO teaching model, using software to learn and using online and offline teaching methods to design content. It is roughly divided into 4 stages. First, the basic stage includes learning and watching a relatively simple, basic combination of basic football moves, such as the combination of passing the ball on the inside of the foot and moving left and right. Second, the development stage includes learning and watching movement skills that are slightly more difficult, such as 20-meter circumnavigation and shooting. Third, the promotion stage includes combining the actions learned in the previous stage in the set competition. Fourth, the application stage includes using them in actual competitions. The control group is designed according to the difficulty of mastering technology or tactics and is roughly divided into 3 stages. First, the basic stage includes learning the basic skills of football. Second, the development stage includes learning basic tactics. Third, the application stage includes the competition application stage. 
TABLE 1: Basic situation of experimental group and control group students $(M \pm S D)$.

\begin{tabular}{|c|c|c|c|c|c|}
\hline Class time & Group & Number & Height & Weight & Age \\
\hline Tuesday (5-6) & Experimental & 26 & $171 . \pm 6.05$ & $70.3 \pm 4.25$ & $19.3 \pm 1.01$ \\
\hline Tuesday (7-8) & Experimental & 25 & $170 . \pm 7.12$ & $71.6 \pm 5.18$ & $19.5 \pm 0.82$ \\
\hline Total & Experimental & 51 & $171 . \pm 6.58$ & $70.9 \pm 4.72$ & $19.4 \pm 0.91$ \\
\hline Tuesday (5-6) & Control & 28 & $170 . \pm 5.12$ & $70.6 \pm 5.23$ & $19.3 \pm 0.72$ \\
\hline Tuesday (7-8) & Control & 29 & $171 . \pm 6.21$ & $70.7 \pm 4.15$ & $19.4 \pm 0.63$ \\
\hline Total & Control & 57 & $170 . \pm 5.32$ & $70.6 \pm 4.69$ & $19.3 \pm 0.67$ \\
\hline
\end{tabular}

(2) Teaching content of each lesson: the teaching content of the experimental group is mainly on the inside of the foot to pass, bump the ball, $20 \mathrm{M}$ around the shot, and kick long. In addition, the learning pass software is used to record teaching videos and the learning pass software is then uploaded. Using flipped classroom, students learn the teaching content of this lesson through the learning software before the class. In the rest interval of classroom teaching, the teacher introduces the teaching content of this lesson in combination with the teaching video of the learning software. The teaching of the control group mainly adopts traditional teaching methods. For example, the teacher first explains the key points of the pass movement on the inside of the foot, as well as the key and difficult points, the teacher's demonstration, and the form of exercises by the students.

\subsubsection{Teaching Process and Procedure Settings}

(1) The teaching process of each lesson: the teaching process of the experimental group and the control group includes three parts, the preparation part, the basic part, and the end part and they are different. During the preparation period, the experimental group had previewed the teaching content of the class through Chaoxing Learning Platform, watched the teaching video, and had a preliminary impression of the teaching content in their minds. During the basic part, the teachers of the experimental group spent less time talking than those of the control group and the students were mainly asked to practice more, interspersed with re-review of the video during the period. Finally, after the course is over, homework will be assigned to the Chaoxing Learning Platform, such as uploading a video of after-school practice of what they have learned. The control group mainly used conventional teaching procedures.

(2) Teaching steps for each exercise: the experimental group adopts the OTO teaching mode to teach. The main steps are preclass preparation, participation in class consolidation after class, and assessment and evaluation (Figure 1).

Among the teaching steps, the main practice method adopted is the motor image learning method. Through the use of the Chaoxing Learning Platform, the learning content is studied before class and the teacher's explanation is combined with the content in the class to carry out structured learning. After class, the content of the class is practiced, a video is recorded, and it is uploaded to the Chaoxing Learning Platform.

The teaching steps of technical exercises in the control group are explanation, demonstration, exercises organization, cycle guidance, and teaching feedback. The teaching content of the second class is taken as an example (Table 2).

2.3.3. Teaching Method. The teaching methods adopted by the experimental group mainly include intuitive teaching method, discovery teaching method, heuristic teaching method, and competition teaching method. The teaching methods adopted by the control group mainly include the demonstration method, the intuitive teaching method, the complete method, and the decomposition method.

\subsection{Experimental Steps}

2.4.1. Pretest. The experimental group and the control group started teaching from the first week of the first semester of the 2020-2021 school year, two hours a week, and the teaching lasted for 16 weeks. In the first week, the students' interest in sports learning was tested through the PE learning interest scale and the technical evaluation standards were used to test the basic technical movements of football (passing on the inside of the foot, kicking far, bumping the ball, 20M shooting around the shot).

2.4.2. Intervention Content. In the process of experimental intervention, the control group used traditional teaching and activity schedules, that is, normal football teaching; the experimental class used the OTO teaching mode for football teaching.

The experimental group carried out a general football course intervention every week. In class, after finishing the preparatory activities, the teaching assistant will use the computer to hold a Tencent meeting and all the students will join the meeting. The assistant will explain the football teaching video online, and the video time is 10 minutes while explaining the technical actions offline. And, questions are asked randomly, for about 10 minutes.

Teaching process includes the following: watching football teaching video (teacher-assisted explanation), practicing without a ball (teacher- and assistant-guided teaching), and practicing with a ball (teacher- and assistantguided practice). 


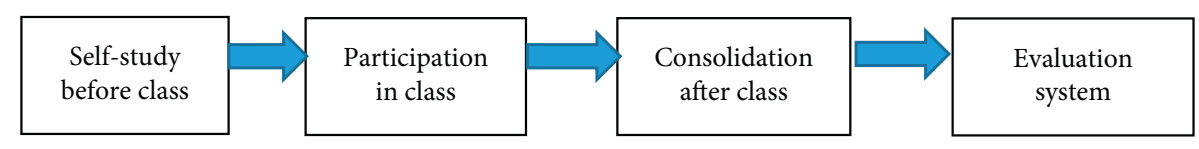

\begin{tabular}{|l|}
\hline $\begin{array}{l}\text { 1. Study task } \\
\text { released }\end{array}$ \\
2. Learning \\
through \\
self-study \\
3. Feedback on \\
self-study \\
\hline
\end{tabular}
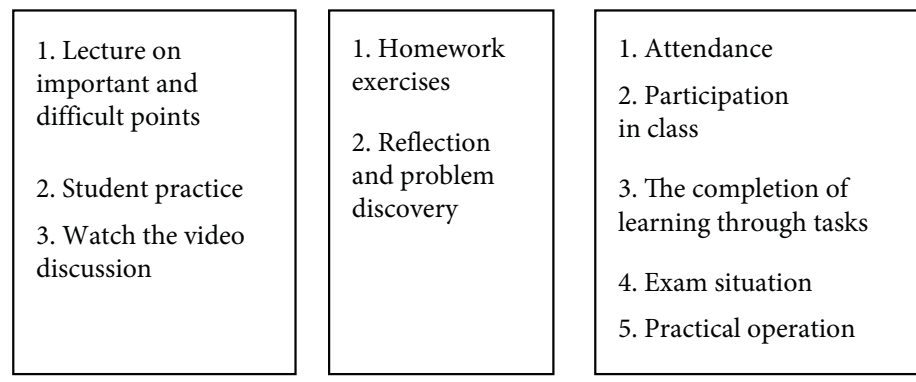

Figure 1: Teaching implementation steps.

TABLE 2: Comparison of the teaching steps of the inside of the football foot between the experimental group and the control group.

\begin{tabular}{|c|c|}
\hline Experimental group & Control group \\
\hline $\begin{array}{l}\text { 1. Preparation before class: the teacher uploads relevant learning } \\
\text { materials such as the syllabus, teaching design, teaching-related } \\
\text { videos, and animations to the Chaoxing Learning Platform course } \\
\text { column for students to preview in advance. Teaching content videos } \\
\text { are published through group mailboxes, OQ, WeChat, etc. }\end{array}$ & $\begin{array}{l}\text { 1. Explanation: the teacher introduces the concept of passing the ball } \\
\text { on the inside of the foot, the action essentials, and the application of } \\
\text { the game. }\end{array}$ \\
\hline $\begin{array}{l}\text { 2. Classroom teaching: the teacher will give a brief explanation after } \\
\text { the demonstration. }\end{array}$ & $\begin{array}{l}\text { 2. Demonstration: the teacher demonstrates the complete pass of the } \\
\text { inside of the football foot. }\end{array}$ \\
\hline $\begin{array}{l}\text { 3. Organizing student exercises: exercises are paired in groups of } 2 \text {, } \\
\text { exercises are paired on the move, and exercises are applied in the } \\
\text { game. }\end{array}$ & $\begin{array}{l}\text { 3. Organizing student exercises: these include ball-free exercises and } \\
\text { fixed ball exercises, exercises are paired in groups of } 2 \text {, and exercises } \\
\text { are paired on the move. }\end{array}$ \\
\hline $\begin{array}{l}\text { 4. Teaching feedback: teacher inspection guidance and error } \\
\text { correction. }\end{array}$ & $\begin{array}{l}\text { 4. Teaching feedback: teacher inspection guidance and error } \\
\text { correction. }\end{array}$ \\
\hline 5. Homework: homework assigned to Chaoxing Learning Platform. & \\
\hline
\end{tabular}

2.4.3. Intervention Implementation and Control. The experimental intervention period of this study is from October 2020 to January 2021, a total of one semester, 16 weeks. At the same time, in order to reduce the impact of time, weather, and other reasons on students' football skills test and PE learning interest test, it is unified to conduct football skills and PE learning interest index tests for the experimental group and the control group in mid-October. Among them, the football skill test includes passing the ball on the inside of the foot, kicking the ball far, bumping the ball, and shooting $20 \mathrm{M}$ around the pole. The PE learning interest evaluation scale includes five indicators: positivity, negativity, skill learning, extracurricular activities, and sports attention. Through a one-semester intervention, in late January 2021, the students will be posttested on football skills and PE learning interests in the same venue, with the same test format and method. The authenticity of the two test data records must be guaranteed.

2.5. Research Tool. Using the "College Student Sports Learning Interest Evaluation Scale" compiled by Gu Haiyong and Jie Chao, the reliability coefficient of the scale is 0.925 , which has very high reliability. The scale uses a 5-point scoring method, ranging from "completely disagree" to "completely agree." The larger the score is, the greater the influence on the behavior will be. The scale contains 5 dimensions:

(i) Positivity includes questions 1, 2, 3, 4, 5, and 6

(ii) Negativity includes questions 7, 8, 9, 10, 11, and 12

(iii) Skills learning includes questions 13, 14, 15, and 16

(iv) After-school activities include questions 17, 18, and 19

(v) Sports attention includes questions 20, 21, 22, 23, and 24 .

\section{Results}

3.1. Before the Experiment, There Was No Significant Difference between the Experimental Group and the Control Group in the Results of the Physical Learning Interest Level Test Items. Before the experiment, the independent sample $T$-test results of students' PE learning interest level showed that there was no significant difference in the five dimensions of positivity, passivity, skill learning, extracurricular activities, and sports attention between the experimental group and the control group. (T positivity $=-0.083, P>0.05$; T negativity $=-0.237$, $P>0.05$; T skill learning $=-0.213, P>0.05$; T extracurricular 
TABLE 3: Before the experiment, the comparison and analysis table of the difference in students' PE learning interest level between the experimental group and the control group $(n=107)$.

\begin{tabular}{|c|c|c|c|c|c|c|}
\hline Test items & Test index & Group & Number & Mean, $\mathrm{M} \pm \mathrm{SD}$ & $\mathrm{T}$ & $P$ \\
\hline \multirow{10}{*}{$\mathrm{PE}$ interest level } & \multirow{2}{*}{ Positivity } & Group 1 & 51 & $1.75 \pm 1.02$ & \multirow{2}{*}{-0.083} & \multirow{2}{*}{0.751} \\
\hline & & Group 2 & 56 & $1.70 \pm 1.04$ & & \\
\hline & \multirow{2}{*}{ Negativity } & Group 1 & 51 & $3.74 \pm 1.30$ & \multirow{2}{*}{-0.237} & \multirow{2}{*}{0.506} \\
\hline & & Group 2 & 56 & $3.79 \pm 1.11$ & & \\
\hline & \multirow{2}{*}{ Skills } & Group 1 & 51 & $4.01 \pm 1.01$ & \multirow{2}{*}{-0.213} & \multirow{2}{*}{0.278} \\
\hline & & Group 2 & 56 & $4.05 \pm 0.97$ & & \\
\hline & \multirow{2}{*}{ Activities } & Group 1 & 51 & $3.78 \pm 1.15$ & \multirow{2}{*}{-1.044} & \multirow{2}{*}{0.428} \\
\hline & & Group 2 & 56 & $4.0 \pm 1.058$ & & \\
\hline & \multirow{2}{*}{ Attention } & Group 1 & 51 & $3.8 \pm 1.165$ & \multirow[t]{2}{*}{0.911} & \multirow[t]{2}{*}{0.368} \\
\hline & & Group 2 & 56 & $3.6 \pm 0.936$ & & \\
\hline
\end{tabular}

Note. Group 1: experimental group; Group 2: control group.

activities $=-1.044, P>0.05$; T sports attention $=0.911, P>0.05$. See Table 3 for details.) This result shows that before the experiment, the students in the experimental group and the students in the control group basically show the same level of interest in sports learning.

\subsection{Analysis on the Differences of Different Dimensions of} Sports Interest between the Experimental Group and the Control Group after the Experiment. After the experiment, the independent sample T-test results of the students' PE learning interest level showed that there were significant differences in the four dimensions of the PE learning interest level of positivity, negativity, skill learning, and extracurricular activities between the experimental group and the control group. The $P$ value of the dimension of sports attention is greater than 0.05 , so there is no significant difference in sports attention. $($ T positivity $=-2.473, P<0.05 ; \mathrm{T}$ negativity $=3.209, \quad P<0.007 ; \quad \mathrm{T}$ skill learning $=2.786$, $P<0.05 ; \mathrm{T}$ extracurricular activities $=2.934, \quad P<0.01 ; \mathrm{T}$ sports attention $=1.119, P>0.05$. See Table 4 for details.) The results show that the online and offline teaching mode can effectively enhance students' interest in sports learning, but it has little effect on sports attention.

\section{Discussion}

The experimental results show that the PE learning interest of the experimental group is significantly higher than that of the control group and its negative interest is significantly lower than that of the control group. It can be concluded that the experimental results support some of the hypotheses put forward by the research. That is to say, the OTO teaching mode with football lessons as the carrier has obvious promotion effect on the positivity of college students' PE learning interest, skill learning, and extracurricular activities and alleviating the negativity of PE learning interest. The reason is that, first of all, compared with the traditional offline teaching action explanation, the OTO teaching mode is a new type of teaching mode. It integrates sound and picture, with high clarity and interest, and can be intuitive to students. The stimulus of the picture makes the students' interest in physical education to gradually increase, so that their learning positivity will be higher [12]. Second, in football teaching, the understanding and mastery of technical movements is the key. The teaching of football technical actions requires a lot of observation, imitation, feedback, and correction in the process of technical action and a lot of perceptual information besides proprioception, such as visual information and auditory information. Online teaching can integrate animations and assist teachers in providing students with various perceptions of three-dimensional space and conducting specific practical exercises offline to form a mixed teaching mode of "online teaching and offline training." In addition, due to factors such as the age and technical level of some teachers, it is impossible to demonstrate some difficult football skills. Multimedia production can solve it as well, and the actions can be decomposed in an orderly manner and displayed from different angles. These undoubtedly play a significant role in promoting the learning of skills. Third, the OTO teaching mode has expanded infinitely in terms of space and time. Students can study the teaching content without restriction before, during, and after class, without being restricted by time and space. Finally, the OTO teaching model can optimize the evaluation mechanism and build a hybrid evaluation mechanism of "online + offline." Online classroom can count student sign-in frequency and online learning time [10]. It provides a reference for the evaluation of the usual grades at the end of the term. A trinity comprehensive evaluation system of "student self-evaluation, student-student mutual evaluation, and teaching evaluation" is introduced offline to complement the online mode to promote the development of students' football skills, thereby enhancing students' interest in sports learning.

The OTO teaching mode also presents some shortcomings in practical application. First of all, the lag of online teaching facilities and technology affects the effect of online teaching. For example, network freezes occur during online teaching, football teaching video resources will have not formed a system, and echoes during the playback process often occur, which affect the effect of online teaching. Second, it is difficult to supervise online teaching, which mainly relies on the consciousness of students [13]. Although there are abundant resources online, due to the constraints of time and space, teachers cannot directly face students and it is difficult to comprehensively, accurately, and timely grasp the learning status of students, which affects the application effect of the OTO teaching mode. 
TABLE 4: Comparison and analysis table of differences in football skill test scores between the experimental group and the control group after the experiment $(n=107)$.

\begin{tabular}{|c|c|c|c|c|c|c|}
\hline Test items & Test index & Group & Number & Mean, $\mathrm{M} \pm \mathrm{SD}$ & $\mathrm{T}$ & $P$ \\
\hline \multirow{10}{*}{$\mathrm{PE}$ interest level } & \multirow{2}{*}{ Positivity } & Group 1 & 51 & $1.11 \pm 0.313$ & \multirow{2}{*}{-2.473} & \multirow{2}{*}{$0.027^{*}$} \\
\hline & & Group 2 & 56 & $1.45 \pm 0.731$ & & \\
\hline & \multirow{2}{*}{ Negativity } & Group 1 & 51 & $4.59 \pm 0.524$ & \multirow{2}{*}{3.209} & \multirow{2}{*}{$0.007^{* *}$} \\
\hline & & Group 2 & 56 & $3.94 \pm 1.024$ & & \\
\hline & \multirow{2}{*}{ Skills } & Group 1 & 51 & $4.65 \pm 0.501$ & \multirow{2}{*}{2.786} & \multirow{2}{*}{$0.014^{*}$} \\
\hline & & Group 2 & 56 & $4.58 \pm 0.968$ & & \\
\hline & \multirow{2}{*}{ Activities } & Group 1 & 51 & $4.36 \pm 0.529$ & \multirow{2}{*}{2.934} & \multirow{2}{*}{$0.005^{* *}$} \\
\hline & & Group 2 & 56 & $3.99 \pm 0.948$ & & \\
\hline & \multirow{2}{*}{ Attention } & Group 1 & 51 & $4.66 \pm 0.544$ & \multirow{2}{*}{1.199} & \multirow{2}{*}{0.280} \\
\hline & & Group 2 & 56 & $4.45 \pm 0.731$ & & \\
\hline
\end{tabular}

Note. ${ }^{*} P<0.05$ has a significant difference; ${ }^{* *} P<0.01$ has an extremely significant difference. Group 1: experimental group; Group 2: control group.

\section{Conclusions and Suggestions}

\subsection{Conclusions}

(1) The implementation of the OTO teaching mode can effectively stimulate the positivity of students' $\mathrm{PE}$ learning interest, skill learning, and extracurricular activities and alleviate the negativity of PE learning interest.

(2) The OTO teaching mode has little effect on sports attention in PE learning interest.

\subsection{Suggestions}

(1) All colleges and universities should actively adopt the OTO teaching mode in physical education, which is conducive to stimulating students' interest in physical education, improving teaching quality, and promoting the reform and development of college physical education courses.

(2) In the course of daily class, you should grasp the time of online class and allow enough time for students to practice.

(3) A diversified evaluation system of evaluation subject, evaluation content, and evaluation dimensions should be adopted in order to obtain more objective, comprehensive, and accurate evaluation results and more accurately reflect the learning situation of students.

\section{Data Availability}

Data sharing is not applicable to this article as no datasets were generated or analyzed during the current study.

\section{Conflicts of Interest}

The authors declare no conflicts of interest.

\section{Acknowledgments}

This work was supported by research grants from the 2020 Education Reform Project of the Hunan Provincial Department of Education (HNJG-2020-0962) and Provincial
“Thirteenth Five-Year" Education Planning Project (XJK18BGD010).

\section{References}

[1] Z. Duan and Y. Tian, "Genetic analysis of learning interest," Educational Science, vol. 28, no. 3, pp. 33-37, 2012.

[2] S. Hidi, "Interest: a unique motivational variable," Educational Research Review, vol. 1, no. 2, pp. 69-82, 2006.

[3] General Office of the State Council, Opinions on Strengthening School Sports to Promote the All-Round Development of Students' Physical and Mental Health, General Office of the State Council of China, Beijing, China, 2016.

[4] X. Niu and J. Yang, "Research on single teaching mode of football," Science and Technology Information, vol. 15, no. 2, pp. 222-223, 2017.

[5] L. Yu, "Analysis of the application of MOOC method in the training of football teachers in vocational colleges," Young people, vol. 83, no. 10, 2019.

[6] L. Yang, "Thoughts on the application of open teaching mode in higher vocational physical education," Journal of Science \& Technology Economics, vol. 27, no. 34, p. 157, 2019.

[7] Y. Xie and H. Hong, "Exploration and thinking on the guiding ideology of public physical education in ordinary colleges and universities," Beijing Sport University News, vol. 37, no. 1, pp. 94-99, 2014.

[8] Y. Ding, "Exploration of OTO teaching mode and management mechanism based on the concept of flipped classroom," Higher Education Management, vol. 10, no. 1, pp. 111-115, 2016.

[9] N. Wang, Y. Dong, L. Yang, and B. Han, "Exploration of college students' social practice management model based on OTO," Modern Economic Information, vol. 452, no. 22, 2015.

[10] M. Dai, H. Zhang, and Y. Liang, "Teaching exploration of online and offline hybrid advanced manufacturing technology training," Laboratory Research and Exploration, vol. 40, pp. 150-153, 2021.

[11] J. Gao, C. Yu, and M. Ma, "Exploration and practice of online teaching of medical immunology under the new coronary pneumonia epidemic," Chinese Journal of Immunology, vol. 36, no. 18, pp. 2200-2204, 2020.

[12] H. Tang and Z. Wang, "The influence of online and offline teaching methods on the learning of basketball special courses in colleges and universities," Sports Science and Technology Literature Bulletin, vol. 28, no. 3, pp. 6-8+ 12, 2020.

[13] Y. Liu, P. Shan, and M. Fan, "How is the "substantial equivalent" of online and offline teaching quality possible," Journal of National Academy of Educational Administration, vol. 3, pp. $67-75,2021$. 